\title{
Structural changes in the labor market and the rise of early retirement in Europe*
}

\author{
Anna Batyrał David de la Croix; Olivier Pierrard’ Henri R. Sneessens $₫$
}

This version: March 2017

\begin{abstract}
The rise of early retirement in Europe is typically attributed to the European system of taxes and transfers. A model with an imperfectly competitive labor market allows us to consider also the effects of bargaining power and of matching efficiency on pre-retirement. We find that lower bargaining power of workers and declining matching efficiency have been important determinants of early retirement in France and Germany. These structural changes, combined with early-retirement transfers and population aging, are also consistent with the joint evolution of employment and unemployment rates, the labor share and the seniority premium.

Keywords: Overlapping Generations, Search Unemployment, Labor Force Participation, Aging, Labor Market Policy and Institutions

JEL-Code: E24, H55, J26, J64
\end{abstract}

\footnotetext{
${ }^{*}$ We are grateful for comments received from the participants of workshops at BCL, UCL and PSE, and annual meetings of SOLE, EEA and EALE. This paper should not be reported as representing the views of the Central Bank of Luxembourg or the Eurosystem. The views expressed are those of the authors and may not be shared by other research staff or policymakers in the Central Bank of Luxembourg or the Eurosystem.

${ }^{\dagger}$ Bogazici University, Istanbul; email: annabatyra@yahoo.fr.

¥Université catholique de Louvain; email:david.delacroix@uclouvain.be

§Banque centrale du Luxembourg; email: Olivier.Pierrard@bcl.lu

『Université catholique de Louvain and Université du Luxembourg;email: henri.sneessens@uni.lu
} 


\section{Introduction}

Many European countries have been concerned about low labor force participation rates of older workers. While population aging is raising crucial questions about the sustainability of the current generous social security systems (Ludwig and Reiter (2010), OECD (2014b)), low participation rates make it more difficult to provide for the retired and pre-retired. In two largest European economies, France and Germany, the participation rate of $45-64$ year old men has declined from 86 to $72 \%$ and from 87 to $84 \%$ since the end of the 60s. In 2013 the labor force participation rates of those aged 55-64 were as low as 52\% in France and 74\% in Germany ${ }^{1}$ (OECD (2013a)). Traditionally, this has been attributed to the European welfare system which, by providing generous retirement and early retirement transfers and by taxing labor income too much, discourages older workers from remaining in the labor market. Although increasing longevity is expected to induce people to work longer as they must save for longer future (Bloom et al. (2014)), generous retirement transfers combined with low retirement and pre-retirement age encourage early exit from the labor force (Gruber and Wise (1998)). Models featuring competitive labor markets succeed well enough in justifying this hypothesis. For example, in Heijdra and Romp (2009) early retirement benefits provide a powerful incentive for workers to retire before the normal retirement age. With labor supply varying both at the intensive and extensive margin, Kindermann et al. (2013) show that pension design has important labor supply consequences. Buyse et al. (2013) link hours worked to pension reforms in thirteen OECD countries.

In this paper we allow for labor market imperfections and investigate whether changes in employment prospects may have further contributed to the rise of early retirement. More specifically, we investigate a possible contribution coming from the decreases in matching efficiency and bargaining power observed in Europe since 1970s. By resulting in downward pressure on wages and discouragement to search, they may have induced older workers out of the labor market. Yet, the importance of these channels remains largely unexplored. The literature rarely points to the bargaining power and matching efficiency as potential determinants of incentives for workers to retire early. Gautié and Schmitt (2010) discuss the impact of institutions on the supply of the low-wage labor, including the elderly. They contrast the Danish approach that provides both human capital and out-of-work income, thus fostering worker's bargaining power, with the more liberal one of the U.S., U.K. and Germany following the Hartz reforms, where unemployed workers are pressured to accept low-wage work and thus may be discouraged from searching for jobs in the first place. Schmitt and Jones (2012) study the rise of bad jobs in the U.S. since 1970s. They argue that the decline in the economy's ability to create good jobs

\footnotetext{
${ }^{1}$ We find similar evolutions in most continental European countries as Belgium, Luxembourg or The Netherlands.
} 
is related to the deterioration in the bargaining power of workers, and has effectively pulled out of the labor market the workers in the middle and bottom of the pay scale. The only theoretical work viewing the bargaining power as determinant of early retirement is Khaskhoussi (2009). In a partial equilibrium model with Nash wage bargaining he emphasizes the effect of incentives to delay retirement when the bargaining power of workers is positive. The literature linking matching efficiency to early retirement is even scarcer. Dickens and Triest (2012) suggest that a potential effect of the lower matching efficiency due to the Great Recession in the U.S. puts older displaced workers at a relatively high risk of prolonged spells of unemployment and premature retirement.

To evaluate the contribution of the bargaining power of labor and matching efficiency in the labor market to early retirement, we introduce the imperfect labor markets as in Pissarides (2000) into the standard overlapping generations (OLG) framework (de la Croix and Michel (2002)) with a twotier pension system, and explicitly model the labor force participation of older workers at the extensive margin. Compared to models with perfect labor market, this set-up allows us to consider the impact of labor market institutions such as retirement benefits and bargaining arrangements, as well as labor market mismatch, not only on the labor force participation of older workers but also on other labor market outcomes such as employment, labor share and seniority premium. Thus we do not study senior labor force participation in isolation. Our setup also allows us to gauge the asymmetric responses to shocks for different age-groups and countries. As a result, we find that lower bargaining power of workers largely contributed to early retirement in France and Germany. However, we find that lower matching efficiency in the labor market had an opposite effect on senior workers' labor force participation. Finally, we need to combine the two structural shocks with old-age transfers and population aging to reproduce the joint evolutions of other labor market variables for senior and junior workers.

Specifically, we consider an economy populated by three generations of agents - junior, senior and retired - who allocate resources between consumption, saving and bequest. Each generation forms a household that ensures perfect risk sharing across individuals of that generation, in line with most literature. Firms and workers engage in costly search for partners in the labor market and, when matched, bargain over wages. All workers are perfect substitutes but their productivity varies with age. Firms do not discriminate between workers of different age and decide on the number of vacancies that can be filled either by the young or old. Job destruction is kept exogenous. While all young are active searchers, central to our analysis is the labor force participation choice of senior workers who face a trade-off between looking for jobs and pre-retiring. Being search active involves a cost in the form of disutility of search but it carries an expected gain from potential employment. Inactivity allows to enjoy full leisure and pre-retirement income form social programs. 
Our model is unique in the sense that it brings together life-cycle consumption and saving and labor market frictions, along with a realistic representation of the demographic process of aging, in order to study the determinants of early retirement in Europe. It belongs to the same family as de la Croix et al. (2013) who extend our simple framework to fifteen generations to study population aging and pension reforms in France. They demonstrate that neglecting labor market frictions and employment dynamics may seriously bias the evaluation of pension reforms when these have an impact on the equilibrium interest rate. Our purpose here is different as we investigate alternative determinants of early retirement, beyond pension schemes. We focus on the declining bargaining power of labor and falling matching efficiency, and ask whether and to what extent they have affected the willingness of older workers to participate in the labor market. We take on the bargaining power of workers because it is now widely accepted that the bargaining power of labor vis-a-vis capital has declined substantially (OECD (2012a)). The most direct factor leading to lower bargaining power of workers has been the changing nature of bargaining arrangements. In France and Germany the index of union density ${ }^{2}$ fell from 21 to 10 and 32 to 27, respectively, between the 1960s and 1990s (Nickell (2003)). By 2010 the index of union density fell further to 20 in Germany (OECD (2012a)). On the other hand, the collective bargaining coverage ${ }^{3}$ in France and Germany remained stable at around 90\% until mid-1990s (Nickell (2003)). However by 2010, while the coverage in France was only slightly lower at 90\%, the coverage in Germany was substantially reduced to $60 \%$, partially due to a larger share of employees under non-standard contracts such as mini-jobs (OECD (2012a)). The changing nature of the globalized economy, demanding larger flexibility in local markets, has made the bargaining process more decentralized. Matching efficiency, the productivity of the process that brings workers and jobs together, has also undergone major shifts since 1970s. Decline in matching efficiency is believed to be behind some of the outward shifts of the Beveridge curve $e^{4}$ in Europe, including in France and Germany (Jackman et al. (1990), Layard et al. (2005)). In Germany Entorf (1998) finds evidence of a greater mismatch resulting from the imbalance between labor demand and supply. Between 1980 and 1997, Fahr and Sunde $(2004,2006)$ find a negative time trend of roughly $-3 \%$ per annum implying a $45 \%$ drop in the matching efficiency over the entire period. Estimations for France also point to a substantial decrease in matching efficiency in 1990s, of which about $30 \%$ can be traced to changes in the composition of unemployed job seekers (Ibourk et al. (2004))..$^{5}$

\footnotetext{
${ }^{2}$ Union density records union members as percentage of employees.

${ }^{3}$ Collective bargaining coverage relates to workers covered by wage bargaining agreements as a proportion of wage and salary earners.

${ }^{4}$ The Beveridge curve is an equilibrium relation that equates flows in with flows out of unemployment. It is downward-sloping in the vacancy-unemployment space (Blanchard and Diamond (1989), Pissarides (2000)). It shifts as a result of changes in matching efficiency, job separation and population growth.

${ }^{5}$ A recent study for the EU (Arpaia et al. (2014)) indicates increases in efficiency starting to appear in Germany around 2008,
} 
Our modeling strategy is close to Hairault et al. (2011) and Chéron et al. (2013) who use a search and matching process similar to that of Mortensen and Pissarides (1994), adapted to include finite lifetimes. However, they do not model participation and aging and labor share cannot be studied because there is no capital accumulation. Hairault et al. (2010) study early-retirement decisions and job search intensities in a search model of McCall (1970) with exogenous wage distribution, extended to include stochastic aging. However, because wages are exogenous, there is no scope here to study the effect of bargaining power on participation; nor can the effect of aging be reproduced reliably as there is no saving. Instead of exogenous wages we introduce wage setting through Nash bargaining between workers and firms, as well as capital accumulation. Khaskhoussi (2009) elaborates on the partial equilibrium model of Hairault et al. (2010) by introducing Nash wage bargaining and thus provides, to our knowledge, the only model predicting that the incentive to pre-retire declines when the worker's bargaining power is positive. However, he ignores capital and thus provides no way to study the labor market jointly with the saving behavior.

\section{The Model}

Time is discrete and runs from zero to infinity. The economy starts with initial conditions bearing on the capital stock and on employment. At each date a single numeraire good is produced from labor and capital.

\subsection{Demographics}

We consider an overlapping generations model. Each cohort lives for three periods (junior, senior and old, respectively indexed $j, s, o$.). The size of a cohort born at time $t$ is equal to 1 . In each period of life agents make different participation decisions:

- all juniors participate in the labor market and search for jobs; they may be be employed or unemployed:

$$
1=N_{t}^{j}+U_{t}^{j}
$$

- the seniors choose to participate or not in the labor market; those who withdraw enter early retirement schemes; total senior population is thus split into three groups - employed, unemployed

possibly due to the Hartz Reforms (Fahr and Sunde (2009)). In France during 2000s one observes a relatively trend-less evolution with cyclical fluctuations. We focus on matching efficiency trends prior to the Great Recession as our exercise is concerned with the period 1968-2007 in order to avoid the conflation with anomalous macro-dynamics arising due to the crisis. 
and inactive:

$$
1=N_{t}^{s}+U_{t}^{s}+I_{t}^{s}
$$

- only a fraction $\sigma$ of a cohort reaches old age; all old people are inactive ("retired"):

$$
\sigma=I_{t}^{o}
$$

\subsection{Labor Market Flows}

We use a Mortensen-Pissarides representation of search frictions. We assume an exogenous job destruction rate $\chi$ and a constant returns to scale matching function. The total number of job seekers at time is equal to:

$$
\Omega_{t}=1+\left(1-I_{t}^{s}\right)\left\{1-(1-\chi) N_{t-1}^{j}\right\}
$$

The pool of job seekers at a time $t$ equals to the new population of junior workers normalized to 1 plus the currently active unemployed senior workers (i.e. those who separated from jobs in the previous period but continue to participate in the labor market in the current period). It is assumed implicitly that the initial employment status of the seniors does not affect their early retirement choice. Given the matching function: ${ }^{6}$

$$
M_{t}=M\left(V_{t}, \Omega_{t}\right)
$$

the probabilities of finding a job and filling a vacancy will be respectively given by:

$$
p_{t}=\frac{M_{t}}{\Omega_{t}} \quad \text { and } \quad q_{t}=\frac{M_{t}}{V_{t}}
$$

The probabilities that a vacancy is filled by a junior and a senior worker are:

$$
q_{t}^{j}=\frac{1}{\Omega_{t}} q_{t} \quad \text { and } \quad q_{t}^{s}=\frac{\Omega_{t}-1}{\Omega_{t}} q_{t} .
$$

\footnotetext{
${ }^{6}$ Although firms may prefer specific workers (young vs. old), they never turn down an application as long the asset value of a job is positive. Therefore imposing exogenously a segmented labor market (two matching functions) would be unrealistic because the firm would have no incentive to refuse a worker from the other segment. It is worth noting that these results would not hold with another kind of production function (workers not being substitutes) and/or with no free entry condition for the firms (see also Pissarides (2000) for a related discussion).
} 
The number of employed junior workers is then equal to:

$$
\begin{aligned}
N_{t}^{j} & =q_{t}^{j} V_{t}, \\
& =p_{t} .
\end{aligned}
$$

From the firm's and the worker's point of view, respectively, the number of employed seniors is:

$$
\begin{aligned}
& N_{t}^{s}=q_{t}^{s} V_{t}+(1-\chi) N_{t-1}^{j}\left(1-I_{t}^{s}\right) \\
& N_{t}^{s}=\left[(1-\chi) N_{t-1}^{j}+p_{t}\left\{1-(1-\chi) N_{t-1}^{j}\right\}\right]\left(1-I_{t}^{s}\right) .
\end{aligned}
$$

These two equations mean that senior employment is the sum of the remaining junior employment from the previous period and the newly created jobs with senior job-seekers.

\subsection{Households}

Each generation forms a household equipped with perfect foresight. Let $c_{t}, d_{t+1}, e_{t+2}$ denote consumption per household member in each period of life of a generation born at time $t$. We allow for bequest $b_{t+2}$, also defined per household member. By this we assume the joy of giving, rather than dynastic altruism. The agents have a probability $\sigma$ of surviving into the last period. The objective function of a representative household is then:

$$
W_{t}^{H}=\max _{c_{t}, d_{t+1}, e_{t+2}, b_{t+2}, I_{t+1}^{s}}\left\{P\left(c_{t}\right)+\beta\left[P\left(d_{t+1}\right)-D\left(N_{t+1}^{s}\right)-D\left(U_{t+1}^{s}\right)\right]+\sigma \beta^{2}\left[P\left(e_{t+2}\right)+V\left(b_{t+2}\right)\right]\right\}
$$

where $P($.$) is the utility of consumption, and D(N)$ and $D(U)$ are disutilities associated with work and search unemployment ${ }^{7}$. Disutility of inactivity is nil. Our objective function is similar to Michel and Pestieau (2013) but it also includes the disutility of job search when unemployed. It is also similar to Docquier et al. (2007) although their labour supply decision is determined by investment in human capital and there are no bequests. The household maximizes its objective function subject to (2) and the following employment flow (13) and budget constraints (14)-(16) for a generation in the three periods of

\footnotetext{
${ }^{7}$ For simplicity we assume the disutilities of work and search only for the seniors since the participation decision concerns only them. What in fact matters is the difference between disutilities of work and search when old and young, so we do as if the disutilities for the young were normalized to zero. We represent the utility of consumption by $P($.$) , instead of U($.$) , to avoid$ confusion with unemployment.
} 
life:

$$
\begin{aligned}
N_{t+1}^{s} & =\left(1-I_{t+1}^{s}\right)\left[(1-\chi) N_{t}^{j}+p_{t+1}\left\{1-(1-\chi) N_{t}^{j}\right\}\right] ; \\
c_{t}+s_{t} & =\sigma R_{t} b_{t-1}+\left(1-\tau_{t}^{j}\right) w_{t}^{j} N_{t}^{j}-T_{t} ; \\
d_{t+1}+z_{t+1} & =R_{t+1} s_{t}+b_{t+1}^{i} I_{t+1}^{s}+\left(1-\tau_{t+1}^{s}\right) w_{t+1}^{s} N_{t+1}^{s}-T_{t+1} ; \\
\sigma e_{t+2}+\sigma b_{t+2} & =R_{t+2} z_{t+1}+\sigma b_{t+2}^{r}-\sigma T_{t+2} .
\end{aligned}
$$

$R_{t}$ is the gross rate of interest. $s_{t}, z_{t+1}$ and $b_{t+2}$ stand for savings in the three periods of life. Bequests $b_{t+2}$ are passed on to the next generation. Inactive senior workers receive an early retirement (inactivity) benefit $b_{t+1}^{i}$. Old workers receive a retirement benefit $b_{t+1}^{r}$. Taxes on wages are $\tau^{j}$ and $\tau^{\mathcal{s}} . T$ is a (positive or negative) lump sum tax per household member and we assume that it does not depend on the generation. These lump sum transfers are set to keep the government budget in equilibrium (see section 2.5). Equation (13), the law of motion of senior employment, is not customary in standard Walrasian OLG models. Here it reflects the constraint laid by the frictional labor market and hence is crucial to the seniors' participation decision. Equation (16) reflects the perfect insurance within the household (generation). It is synonymous with the postulate of an annuity market by the means of which the wealth of those who die with probability $1-\sigma$ is redistributed among their brothers and sisters. The first order optimality conditions associated with this optimization programme are:

$$
\begin{aligned}
P_{c_{t}} & =\beta R_{t+1} P_{d_{t+1}} ; \\
P_{d_{t+1}} & =\beta R_{t+2} P_{e_{t+2}} ; \\
P_{e_{t+2}} & =V_{b_{t+2}} ; \\
b_{t+1}^{i} & =\pi_{t+1}^{s}\left[\left(1-\tau_{t+1}^{s}\right) w_{t+1}^{s}-\frac{D_{N_{t+1}^{s}}}{P_{d_{t+1}}}\right]-\left(1-\pi_{t+1}^{s}\right) \frac{D_{U_{t+1}^{s}}}{P_{d_{t+1}}} .
\end{aligned}
$$

(17)-(18) describe the optimal consumption profile. (19) represents the tradeoff between utility from old-age consumption and the joy of leaving a bequest. Equation (20) determines the participation rate of the seniors. We define $\pi_{t}^{s}=\frac{N_{t}^{s}}{1-I_{t}^{s}}$ as the probability of a senior to be employed. The seniors compare the cost and benefit of being active. The cost is the pre-retirement benefit receipt forgone when exiting inactivity. The gain is the expected income from being active - the weighted average of income from employment and unemployment. The former includes the wage after tax, less the disutility of work. The latter is the disutility of search when unemployed. For simplicity we abstract from unemployment benefits. Equation (20) implies that, at given wage and early-retirement benefits, a lower matching 
efficiency leads to a lower participation rate $(1-I)$ by reducing the probability $\pi$ of being employed.

The values for the household of an additional junior or senior job, calculated from (12) subject to constraints (13)-(15), are as follows:

$$
\begin{aligned}
\frac{\partial W_{t}^{H}}{\partial N_{t}^{j}} \frac{1}{P_{c_{t}}}= & \left(1-\tau_{t}^{j}\right) w_{t}^{j} \\
& +\tilde{\beta}_{t+1}\left(1-p_{t+1}\right)(1-\chi)\left(1-I_{t+1}^{s}\right)\left[\left(1-\tau_{t+1}^{s}\right) w_{t+1}^{s}-\frac{D_{N_{t+1}^{s}}-D_{U_{t+1}^{s}}}{P_{d_{t+1}}}\right] ; \\
\frac{\partial W_{t-1}^{H}}{\partial N_{t}^{s}} \frac{1}{P_{d_{t}}}= & {\left[\left(1-\tau_{t}^{s}\right) w_{t}^{s}-\frac{D_{N_{t}^{s}}-D_{U_{t}^{s}}}{P_{d_{t}}}\right], }
\end{aligned}
$$

where the discount factor $\tilde{\beta}_{t+1}$ is defined by:

$$
\tilde{\beta}_{t+1}=\beta \frac{P_{d_{t+1}}}{P_{c_{t}}} .
$$

The first term of (21) means that in the current period the household gains the after-tax wage. The second term of (21) represents the value of being employed today that carries into the next period. If a worker is not separated with probability $\chi$ or does not pre-retire with probability $I_{t+1}^{s}$, when senior he earns the after-tax wage less the disutility of work. The value of being employed today is lower when the probability of getting matched again in the second period $p_{t+1}$ is high, that is when the gain from employment when senior can be obtained with higher probability by taking part in matching again rather than by holding on to the old match. (22) represents the after-tax wage earned by a senior worker. Both values will be used in the wage bargaining.

\subsection{Firms}

There are two productive factors, labor and capital. Senior workers are more productive than junior workers by a factor $\lambda$. Firms rent capital at cost $R_{t}$. The representative firm maximizes the discounted value of dividends (profits) that will be distributed to shareholders. Profits at time $t$ are given by:

$$
\Pi_{t}=F\left(K_{t}, N_{t}^{j}+\lambda N_{t}^{s}\right)-\left(1+\zeta_{t}^{j}\right) w_{t}^{j} N_{t}^{j}-\left(1+\zeta_{t}^{s}\right) w_{t}^{s} N_{t}^{s}-R_{t} K_{t}-a V_{t}
$$

The value of the firm can thus be written as:

$$
\begin{aligned}
W_{t}^{F}=\max _{K_{t}, V_{t}}\left\{F\left(K_{t}, N_{t}^{j}+\lambda N_{t}^{s}\right)\right. & -\left(1+\zeta_{t}^{j}\right) w_{t}^{j} N_{t}^{j}-\left(1+\zeta_{t}^{s}\right) w_{t}^{s} N_{t}^{s} \\
& \left.-R_{t} K_{t}-a V_{t}\right\}+\tilde{\beta}_{t+1} W_{t+1}^{F}
\end{aligned}
$$


subject to (8) and (10). Firm's discount factor (23) maximizes household welfare. $F($.$) is a CRTS produc-$ tion function, $\zeta$ is employer taxation, $a$ is per-period vacancy cost. The first-order optimality conditions yield $^{8}$

$$
\begin{aligned}
R_{t}= & F_{K_{t}} \\
a= & q_{t}^{s}\left[F_{N_{t}^{s}}-\left(1+\zeta_{t}^{s}\right) w_{t}^{s}\right]+ \\
& q_{t}^{j}\left[\left(F_{N_{t}^{j}}-\left(1+\zeta_{t}^{j}\right) w_{t}^{j}\right)+\tilde{\beta}_{t+1}(1-\chi)\left(1-I_{t+1}^{s}\right)\left(F_{N_{t+1}^{s}}-\left(1+\zeta_{t+1}^{s}\right) w_{t+1}^{s}\right)\right] .
\end{aligned}
$$

While (26) is standard, (27) is a vacancy creation condition. The firm sets the cost of opening a vacancy equal to the expected gain from filling it by a senior or junior worker. Employing a junior has a dynamic component since, by the means of equations (8) and (10), next-period employment of the seniors depends on the current level of vacancies. By (10), senior employment depends on current junior employment. By (8), current junior employment depends on the number of current vacancies.

The values for the firm of an additional junior and senior job, that will enter into the wage bargaining problem, can then be calculated as follows:

$$
\begin{aligned}
\frac{\partial W_{t}^{F}}{\partial N_{t}^{j}}= & {\left[F_{N_{t}^{j}}-\left(1+\zeta_{t}^{j}\right) w_{t}^{j}\right] } \\
& +\tilde{\beta}_{t+1}(1-\chi)\left(1-I_{t+1}^{s}\right)\left[F_{N_{t+1}^{s}}-\left(1+\zeta_{t+1}^{s}\right) w_{t+1}^{s}\right] ; \\
\frac{\partial W_{t}^{F}}{\partial N_{t}^{s}}= & F_{N_{t}^{s}}-\left(1+\zeta_{t}^{s}\right) w_{t}^{s} .
\end{aligned}
$$

\subsection{The Government}

We assume that retirement and early retirement (inactivity) benefits are respectively equal to a fraction $\rho^{r}$ and $\rho^{i}$ of current senior wages. ages are taxed at flat rates zeta and tau for employers and employees respectively. The rates can a priori be different for junior and senior workers wages. To avoid issues related to public debt, we assume that the lump-sum tax $T$ adjusts to balance the budget in every period. The value of $T_{t}$ is thus such that the following equality holds true:

$$
\begin{aligned}
& \rho^{i} w_{t}^{s} I_{t}^{s}+\rho^{r} w_{t}^{s} I_{t}^{o}=\left(\zeta_{t}^{j}+\tau_{t}^{j}\right) w_{t}^{j} N_{t}^{j}+\left(\zeta_{t}^{s}+\tau_{t}^{s}\right) w_{t}^{s} N_{t}^{s}+(2+\sigma) T_{t} . \\
& { }^{8} F_{K_{t}}=F_{K_{t}}\left(K_{t}, N_{t}^{j}+\lambda N_{t}^{s}\right), F_{N_{t}^{j}}=F_{N_{t}^{j}}\left(K_{t}, N_{t}^{j}+\lambda N_{t}^{s}\right), F_{N_{t}^{s}}=F_{N_{t}^{s}}\left(K_{t}, N_{t}^{j}+\lambda N_{t}^{s}\right) .
\end{aligned}
$$




\subsection{Wages}

Wages are renegotiated in every period. They are determined by a standard Nash bargaining rule, for junior and senior workers separately. All workers' bargaining power is $\eta$.

\section{Senior Worker Wage}

The generalized Nash product for a senior worker is:

$$
\max _{w_{t}^{s}}\left(\frac{\partial W_{t}^{F}}{\partial N_{t}^{s}} P_{d_{t}}\right)^{1-\eta}\left(\frac{\partial W_{t-1}^{H}}{\partial N_{t}^{s}}\right)^{\eta}
$$

The first-order optimality condition can then be written:

$$
(1-\eta) \frac{1}{P_{d_{t}}} \frac{\partial W_{t-1}^{H}}{\partial N_{t}^{s}}=\eta \frac{1-\tau_{t}^{s}}{1+\zeta_{t}^{s}} \frac{\partial W_{t}^{F}}{\partial N_{t}^{s}}
$$

Marginal employment values have been defined in equations (22) and (29). After substitution, one obtains:

$$
(1-\eta)\left[\left(1-\tau_{t}^{s}\right) w_{t}^{s}-\frac{D_{N_{t}^{s}}-D_{U_{t}^{s}}}{P_{d_{t}}}\right]=\eta\left[\frac{1-\tau_{t}^{s}}{1+\zeta_{t}^{s}} F_{N_{t}^{s}}-\left(1-\tau_{t}^{s}\right) w_{t}^{s}\right]
$$

Let us denote by $\mathcal{S}_{t}^{s}$ the total surplus (net of wage taxes) associated with the employment of a senior worker:

$$
\mathcal{S}_{t}^{s}=\frac{1-\tau_{t}^{s}}{1+\zeta_{t}^{s}} F_{N_{t}^{s}}-\frac{D_{N_{t}^{s}}-D_{U_{t}^{s}}}{P_{d_{t}}}
$$

Using this definition, (32) yields:

$$
\left(1-\tau_{t}^{s}\right) w_{t}^{s}=\frac{D_{N_{t}^{s}}-D_{U_{t}^{s}}}{P_{d_{t}}}+\eta \mathcal{S}_{t}^{s}
$$

The net wage of a senior worker is the sum of the reservation wage plus a fraction $\eta$ of the total surplus.

\section{Junior Worker Wage}

The Nash product for a junior worker is:

$$
\max _{w_{t}^{j}}\left(\frac{\partial W_{t}^{F}}{\partial N_{t}^{j}} P_{c_{t}}\right)^{1-\eta}\left(\frac{\partial W_{t}^{H}}{\partial N_{t}^{j}}\right)^{\eta} .
$$


The first-order optimality condition can then be written:

$$
(1-\eta) \frac{1}{P_{c_{t}}} \frac{\partial W_{t}^{H}}{\partial N_{t}^{j}}=\eta \frac{1-\tau_{t}^{j}}{1+\zeta_{t}^{j}} \frac{\partial W_{t}^{F}}{\partial N_{t}^{j}}
$$

Marginal employment values have been defined in equations (21) and (28). After substitution, one obtains:

$$
\begin{aligned}
& (1-\eta)\left\{\left(1-\tau_{t}^{j}\right) w_{t}^{j}+\tilde{\beta}_{t+1}\left(1-p_{t+1}\right)(1-\chi)\left(1-I_{t+1}^{s}\right) \eta S_{t+1}^{s}\right\} \\
= & \eta\left\{\left[\frac{1-\tau_{t}^{j}}{1+\zeta_{t}^{j}} F_{N_{t}^{j}}-\left(1-\tau_{t}^{j}\right) w_{t}^{j}\right]+\tilde{\beta}_{t+1}(1-\chi)\left(1-I_{t+1}^{s}\right) \frac{1-\tau_{t}^{j}}{1-\tau_{t+1}^{s}} \frac{1+\zeta_{t+1}^{s}}{1+\zeta_{t}^{j}}(1-\eta) S_{t+1}^{s}\right\} .
\end{aligned}
$$

Let us denote by $\mathcal{S}_{t}^{j}$ the total surplus (net of wage taxes) associated with the employment of a junior worker:

$$
\mathcal{S}_{t}^{j}=\frac{1-\tau_{t}^{j}}{1+\zeta_{t}^{j}} F_{N_{t}^{j}}
$$

Using this definition and solving for the net wage yields:

$$
\left(1-\tau_{t}^{j}\right) w_{t}^{j}=\eta \mathcal{S}^{j}+\eta(1-\chi)\left(1-I_{t+1}^{s}\right) \frac{(1-\eta) \mathcal{S}_{t+1}^{s}}{R_{t+1}}\left[\left(\frac{\left(1+\zeta_{t+1}^{s}\right) /\left(1-\tau_{t+1}^{s}\right)}{\left(1+\zeta_{t}^{j}\right) /\left(1-\tau_{t}^{j}\right)}-1\right)+p_{t+1}\right]
$$

The net wage of a junior worker is equal to his reservation wage ( 0 in this case since there is no unemployment benefit and no work disutility), a fraction $\eta$ of the current surplus $\mathcal{S}^{j}$ and a fraction $\eta$ of the discounted value of the surplus the firm expects to obtain tomorrow with the same worker if he remains employed, weighted by a measure of distortion between senior and junior taxes and employment probability of an unemployed $p_{t+1}$.

The intuition behind the junior wage equation is as follows. If the tax wedge is larger for senior workers, firms make more profit when they hire a junior worker. This has a positive impact on junior wages. Now turn to the effect of tomorrow's employment probability $p_{t+1}$. First consider the extreme case where $p_{t+1}$ is equal to 1 , so that having a job today adds nothing to the expected future income of a junior worker, although its brings extra positive value for the firm because the job will survive till next period $\left((1-\chi)\left(1-i_{t+1}^{s}\right)>0\right)$. Wage bargaining then gives a junior worker a fraction $\eta$ of that extra value. At the other extreme, if worker's future employment probability is zero $\left(p_{t+1}=0\right)$, having a match today provides an expected benefit tomorrow for both the firm and worker. Given the bargaining process that will take place tomorrow, these extra future gains turn out to be the same for both parties (see (32)), and so would not affect the current bargained wage. In general though, the worker's future 
employment probability is positive and smaller than $1\left(0<p_{t+1}<1\right)$ and the expected future surplus associated with a job affects the junior wage.

\section{Seniority Wage premium ${ }^{9}$}

The wage equations can be combined to obtain the seniority premium. Taking the difference between senior and junior wages, and focusing on stationary state (to simplify the notation), one obtains:

$$
\begin{aligned}
\left(1-\tau^{s}\right) w^{s}-\left(1-\tau^{j}\right) w^{j}=\left[\frac{D_{N}-D_{U}}{P_{d}}\right]+\eta\left(\mathcal{S}^{s}-\mathcal{S}^{j}\right) & \\
- & \eta(1-\chi)\left(1-I^{s}\right) \frac{(1-\eta) \mathcal{S}^{s}}{R}\left[\left(\frac{\left(1+\zeta^{s}\right) /\left(1-\tau^{s}\right)}{\left(1+\zeta^{j}\right) /\left(1-\tau^{j}\right)}-1\right)+p\right] .
\end{aligned}
$$

The first and most important component of the premium is the difference in reservation wages, which in our model equals the disutility of work for senior workers as the corresponding disutility for the young is assumed nil. The second is related to the difference between the employment surpluses. This term reflects again the differences in reservation wages, as well as in the productivities of the seniors and juniors. It can be positive or negative. When the senior worker's reservation wage (disutility of work) is large, the term can be negative. The last term corresponds to the fraction of the senior surplus that is already included in the junior's wage (see the second term in equation 37). It is affected by the probability of finding a job $p$ and the participation rate $\left(1-I^{s}\right)$.

\section{Bargaining Power}

Equation (38) implies an ambiguous relationship between bargaining power $(\eta)$ and seniority premium. The ambiguity is mainly associated with the second term of the equation. If it is positive, a lower bargaining power will produce a lower seniority premium. The opposite holds true when the term is negative. Because we assume that the senior worker is more productive $(\lambda>1)$, the difference between the two cases comes from the senior worker's disutility of work. When the senior worker's labour disutility (reservation wage) is large relative to the junior one, the senior worker's wage becomes much less sensitive to bargaining power changes. Hence lower bargaining power hits mostly junior workers and increases the seniority premium.

To illustrate that, assume steady state and no taxes. Senior and junior wages in (35) and (38) then simplify, respectively, to:

$$
w^{\mathcal{s}}=\eta \lambda F_{N}+(1-\eta) \frac{D_{N}-D_{U}}{P_{d}}
$$

\footnotetext{
${ }^{9}$ Not strictly in conventional sense, as not due to experience or human capital accumulation.
} 
Figure 1: Wages (drawn for $\lambda>1$ as in the calibration)

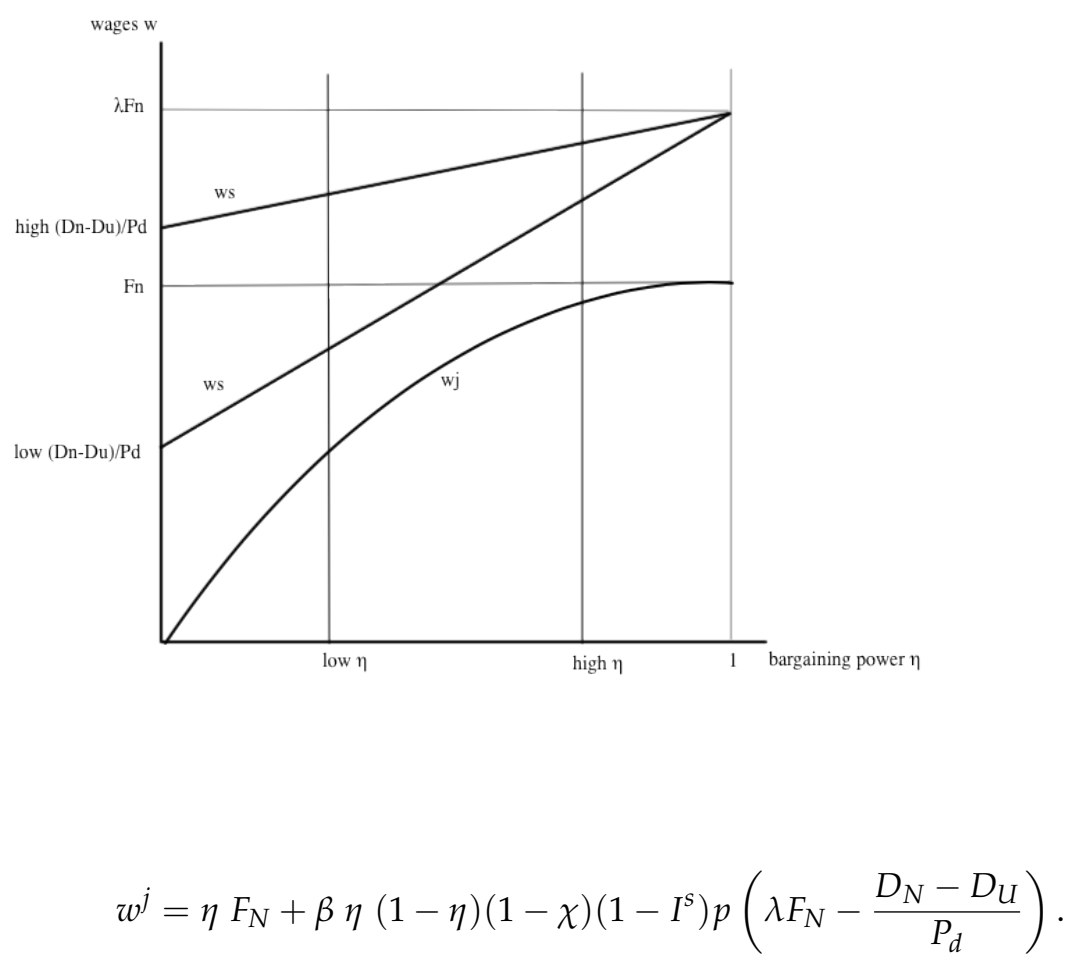

Wages are drawn in Figure 1. For a given inactivity rate $I^{s}$ and a job finding probability $p$ (or effectively for a market tightness $\theta=\frac{V}{\Omega}$ as $p$ is a function of $\theta$ ), both wages are increasing in the worker's bargaining power $\eta: \frac{\partial w^{s}}{\partial \eta}>0$ and $\frac{\partial w^{j}}{\partial \eta}>0$. When $\eta=0$, wages are equal to the disutility of work (no disutility is assumed for junior workers). When $\eta=1$, wages are equal to labor productivity (labor productivity is assumed higher for senior workers). A change in the bargaining power (for instance an increase from low to high $\eta$ ) has an ambiguous effect on the seniority premium. When the gap between work and search disutility is low, such a change may increase the seniority premium. When the gap is high, the same change may decrease it. For some bargaining power values the seniority premium could even be negative, for instance when the disutility differential is low, or $\lambda$ close to 1 (i.e. when the productivity of seniors is not much higher than the productivity of juniors).

\subsection{Equilibrium}

Let $Q_{t}$ denote the total financial value of firms at time $t$. In our deterministic setup, the return on equities must be equal to the market interest rate. In other words, the value of equities must be such that:

$$
\frac{Q_{t+1}+\Pi_{t+1}}{Q_{t}}=R_{t+1}
$$


We implicitly assume capital depreciation rate equal to 1 . The equilibrium on the capital market then implies:

$$
K_{t+1}+Q_{t}=s_{t}+z_{t}+\sigma b_{t}
$$

\section{Calibration - Year 1968}

We use the following functional forms: Cobb-Douglas forms for the matching and production functions, logarithmic forms for the utilities of consumption and bequest, and linear forms for the disutilities of work and search — reflecting a perfect risk-sharing in the household:

$$
\begin{array}{cc}
M\left(V_{t}, \Omega_{t}\right)=\bar{m} V_{t}^{\alpha} \Omega_{t}^{1-\alpha} & F\left(K_{t}, N_{t}\right)=\epsilon K_{t}^{\mu} N_{t}^{1-\mu} \\
P(.)=\ln (.) & V\left(b_{t}\right)=\vartheta \ln \left(b_{t}\right) \\
D\left(N_{t}\right)=D^{n} N_{t} & D\left(U_{t}\right)=D^{u} U_{t} .
\end{array}
$$

We calibrate the model for France and Germany in 1968, the initial steady state. A period is 20 years, 80 quarters. One can think of generations of 25-45 (junior), 45-65 (senior) and 65-85 (retired) years old. The pre-retirement concerns the second half of the second period (55-65) and so the data pertaining to pre-retirement can be easily averaged out over the 20 -year period. The calibrated parameters fall into three categories: (i) the standard values found in the models of this type (2 parameters: the elasticity of matches with respect to vacancies $\alpha$ and the discount rate $\beta$ ); (ii) the parameters specific to this particular model for which we have some empirical information (6 parameters: two replacement ratios $\rho^{i}$ and $\rho^{r}$, the survival probability $\sigma$, the productivity differential $\lambda$ and tax rates $\tau$ and $\zeta$ ); (iii) the parameters specific to this model for which we do not have direct information but which we fix so that the model reproduces the steady states similar to the French and German economies (6 parameters: the matching efficiency $\bar{m}$, the job separation rate $\chi$, the vacancy $\cos t a$, the elasticity of output with respect to capital $\mu$, the bargaining power $\eta$, and the parameters in the disutility of work and search $D^{n}-D^{u}$.). Table 1 summarizes the parameters.

The standard calibrated values (i) are the following: the elasticity of matches with respect to vacancies $\alpha$ set at 0.5 , the usual value used in literature; and the discount factor $\beta$ set at 0.45 so that it corresponds to the quarterly discount factor of 0.99 . The data driven parameters (ii) are as follows. The pre-retirement and retirement replacement ratios, $\rho^{i}$ and $\rho^{r}$, are respectively 0.43 and 0.75 for France and 0 and 0.6 for Germany, based on Duval (2003). In 1968 the survival probability at 65 for the next 20 years 
Table 1: Calibration: Year 1968

\begin{tabular}{|c|c|c|c|c|c|c|}
\hline Parameters & France & & & & & \\
\hline (i) Standard & $\begin{array}{c}\alpha \\
0.5\end{array}$ & $\begin{array}{c}\beta \\
0.99^{80}\end{array}$ & & & & \\
\hline (ii) Empirical & $\begin{array}{c}\rho^{i} \\
0.215^{*}\end{array}$ & $\begin{array}{c}\rho^{r} \\
0.75\end{array}$ & $\begin{array}{c}\sigma \\
0.62\end{array}$ & $\begin{array}{c}\lambda \\
1.1\end{array}$ & $\begin{array}{c}\tau \\
0.118\end{array}$ & $\begin{array}{c}\zeta \\
0.118\end{array}$ \\
\hline (iii) Implied & $\begin{array}{c}\bar{m} \\
0.98\end{array}$ & $\begin{array}{c}\chi \\
0.9\end{array}$ & $\begin{array}{c}\mathrm{a} \\
3.11\end{array}$ & $\begin{array}{c}\mu \\
0.3\end{array}$ & $\begin{array}{c}\eta \\
0.79\end{array}$ & $\begin{array}{c}D^{n}-D^{u} \\
0.75\end{array}$ \\
\hline \multicolumn{7}{|l|}{ Steady state } \\
\hline $\begin{array}{c}\text { Variables } \\
\text { Model/Data }\end{array}$ & $\begin{array}{c}U^{j} \\
0.02\end{array}$ & $\begin{array}{c}N^{S} \\
0.84\end{array}$ & $\begin{array}{c}I^{S} \\
0.14\end{array}$ & $\begin{array}{c}K / F \\
0.135^{* *}\end{array}$ & $\begin{array}{c}L S \\
0.672\end{array}$ & $\begin{array}{c}w^{s} / w^{j} \\
1.3\end{array}$ \\
\hline Parameters & Germany & & & & & \\
\hline (i) Standard & $\begin{array}{c}\alpha \\
0.5\end{array}$ & $\begin{array}{c}\beta \\
0.99^{80}\end{array}$ & & & & \\
\hline (ii) Empirical & $\begin{array}{l}\rho^{i} \\
0\end{array}$ & $\begin{array}{l}\rho^{r} \\
0.6\end{array}$ & $\begin{array}{c}\sigma \\
0.6\end{array}$ & $\begin{array}{c}\lambda \\
1.1\end{array}$ & $\begin{array}{c}\tau \\
0.155\end{array}$ & $\begin{array}{c}\zeta \\
0.155\end{array}$ \\
\hline (iii) Implied & $\begin{array}{c}\bar{m} \\
0.99\end{array}$ & $\begin{array}{c}\chi \\
0.9\end{array}$ & $\begin{array}{c}a \\
5.43 \\
\end{array}$ & $\begin{array}{c}\mu \\
0.3\end{array}$ & $\begin{array}{c}\eta \\
0.75 \\
\end{array}$ & $\begin{array}{c}D^{n}-D^{u} \\
0.03\end{array}$ \\
\hline \multicolumn{7}{|l|}{ Steady state } \\
\hline $\begin{array}{c}\text { Variables } \\
\text { Model/Data }\end{array}$ & $\begin{array}{c}U^{j} \\
0.01\end{array}$ & $\begin{array}{c}N^{S} \\
0.87\end{array}$ & $\begin{array}{c}I^{S} \\
0.125\end{array}$ & $\begin{array}{c}K / F \\
0.135^{* *}\end{array}$ & $\begin{array}{c}L S \\
0.641\end{array}$ & $\begin{array}{c}w^{s} / w^{j} \\
1.1\end{array}$ \\
\hline
\end{tabular}


was $\sigma=0.62$ for France and $\sigma=0.6$ for Germany (Vallin and Meslé (2002) and MaxPlanckInstitute (2009)). We assume that in both countries the old are $10 \%$ more productive than the young $(\lambda=1.1)$, based on Aubert and Crépon (2003) and Skirbekk (2004). Wage taxation refers to social security charges levied on workers and firms. The rates are set equal for all workers and firms $(\zeta=\tau)$ at 0.118 for France and 0.155 for Germany, based on the earliest historical data available (OECD (2004)).

Finally in the category (iii), we match the junior unemployment rates in 1968 at 0.02 in France and 0.01 in Germany by setting the matching efficiency $\bar{m}$ to 0.98 and 0.99 respectively. The 20 -year period job separation rate $\chi$ is set to 0.9 in both cases to match the senior employment rate of 0.84 in France and 0.875 in Germany. The vacancy cost per period $a=3.11$ in France and 5.43 in Germany allows to obtain by equation (27) the senior inactivity rates of 0.14 in France and 0.125 in Germany. All labor market data come from OECD (2013a) for men. Note that the senior employment and inactivity rates imply senior unemployment rates of 0.02 and 0.01 in France and Germany respectively. The elasticity of output with respect to capital $\mu$ is set at 0.3 for both countries to obtain the capital-output ratio of 2.7 on the annual basis. Worker's bargaining power $\eta$ is set at 0.79 and 0.75 . It allows to match the labor share of 0.672 in France and 0.641 Germany. Like in Bentolila and Saint-Paul (2003), Daudey and Decreuse (2006) and OECD (2012a) we focus the labor share corresponding to the business sector, which includes an imputed labor remuneration for the self-employed. The difference between the marginal disutility of work and search $D^{n}-D^{u}$ is 0.75 in France and 0.03 in Germany, calculated to reproduce the ratios of old to young wages of 1.3 and 1.1 respectively (Lazear and Shaw (2009)).

\section{Rise of early retirement: 1968-2007}

While the first column of Table 2 recalls the levels of key labor market variables in 1968, the second column "Data (1968-2007)" shows that the labor market both in France and Germany has undergone dramatic changes over the four decades. The participation rate, as well as the employment rate, of senior workers fell. Contrary to the common wisdom, this exit of seniors from the labor force was not accompanied by a rise in the employment rate of junior workers. At the same time, an increase in the seniority premium and a fall in the labor share were observed.

Throughout the same period, European labor markets were hit by different shocks. Two are well known: (i) a widespread use of early retirement schemes, and (ii) population aging; two additional ones have been well documented but have been less frequently mentioned in the context of early retirement: (iii) a decline in the bargaining power of labor, and (iv) an increase in the heterogeneity of workers and jobs leading to lower matching efficiency. We perform a number of numerical simulations for French 
and German economies between 1968 and 2007 to understand if the mentioned shocks, individually or together, can explain the observed evolutions of the labor market variables, in particular the rise of early retirement ${ }^{10}$. We start by considering the observed shocks to early-retirement transfers and longevity. Next we quantify and analyse the unobserved shocks to the bargaining power of labor and matching efficiency. Table 3 summarizes the shocks under our consideration. Throughout the simulations we adjust lump-sum taxes $T_{t}$ to balance the government budget and avoid issues related to public debt; all other parameters remain the same. In all simulations, technically we assume unanticipated and permanent shocks that take place progressively (and equally) in both periods.

\subsection{Transfers and longevity shocks: calibration and predictions}

Shocks to pre-retirement benefits and longevity are directly observable. Seen in Table 3, the pre-retirement replacement rates $\rho^{i}$ increased from 0.43 in 1968 to 0.64 in 2007 (or from 0.215 to 0.32 if taken over a 20year period) in France and from 0 to 0.15 (or from 0 to 0.075 over a 20-year period) in Germany (Duval (2003)). The longevity $\sigma$, measured as the survival probability at 65 over the following 20 years, rose by 46.8\% in France and 41.7\% in Germany (Vallin and Meslé (2002) and MaxPlanckInstitute (2009)).

The effect of old-age welfare and aging on early retirement have been widely studied in the literature. Generous retirement benefits are believed to encourage early retirement, while longevity encourages labor force participation in order for the elderly to save for a longer future. Using the model, we explore how the two have affected the senior labor force participation, but also confront their effect on other labor market variables - the senior and junior employment rates, seniority premium and labor share. Scenario (i) in Table 2 shows the impact of the rising early-retirement replacement ratios on the labor market. As expected, in both countries the seniors pull out from the labor market and their participation and employment rates fall, which corresponds well to the actual evolutions, although the magnitudes are too strong. However, contrary to the data and due to lower job competition from the seniors, the employment of the young rises. ${ }^{11}$ The effect on wages, both for the senior and the junior workers, is weak and the seniority premium and labor share remain almost unchanged. Thus, while old-age transfers have a potential to explain the rise in early retirement, they are insufficient to account for other labor market variables.

Column (ii) in Table 2 presents the effect of population aging. The impact on senior participation rates is positive, which is consistent with the findings in the existing literature. As households save more

\footnotetext{
${ }^{10} 1968$ to 2007 corresponds to exactly two periods in our model, and 2007 corresponds to pre-crisis level allowing us to abstract from anomalies caused by the great recession.

${ }^{11}$ Ceteris paribus this shocks leads to an unrealistic high expansion of junior employment. Some individual shocks in our simulations lead to unrealistic changes in endogenous variables, hence the importance of providing a larger picture with the full set of shocks.
} 
Table 2: Simulations

\begin{tabular}{|c|c|c|c|c|c|c|c|c|}
\hline & Data/Model & Data & $\begin{array}{c}\text { Transfers } \\
\rho^{i}\end{array}$ & $\begin{array}{c}\text { Longevity } \\
\sigma\end{array}$ & $\begin{array}{c}\text { Transfers } \\
\text { Longevity } \\
\rho^{i}, \sigma\end{array}$ & $\begin{array}{c}\text { Bargaining } \\
\text { power } \\
\eta\end{array}$ & $\begin{array}{c}\text { Matching } \\
\text { efficiency } \\
\bar{m}\end{array}$ & $\begin{array}{l}\text { Full model } \\
\rho^{i}, \sigma, \bar{m}, \eta\end{array}$ \\
\hline & 1968 & $1968-2007$ & (i) & (ii) & (iii) & (iv) & (v) & (vi) \\
\hline Senior part. rate & 86 & -17 & -34.6 & +19 & -21 & -46.6 & +43.8 & -14.7 \\
\hline Senior emp. rate & 84 & -19 & -25.9 & +16.5 & -11.5 & -15.8 & -15.2 & -17.9 \\
\hline Junior emp. rate & 98 & -5 & +17.7 & -2.3 & +15.7 & +87.9 & -48.5 & -5.3 \\
\hline \multicolumn{9}{|l|}{ Germany } \\
\hline Senior part. rate & 87.5 & -6 & -14 & +16.2 & +0.8 & -7.6 & +1 & -7.3 \\
\hline Senior emp. rate & 87 & -15 & -12.9 & +17.5 & +3.2 & +11.1 & -24.2 & -14.6 \\
\hline Junior emp. rate & 99 & -8 & +1.5 & +1.5 & +3 & +26.2 & -31.2 & -10.2 \\
\hline
\end{tabular}

Results expressed in percentage point deviation from the initial steady state; senior part. rate $=1-I^{s}$, senior unemp. rate $=$ $U^{s} /\left(1-I^{s}\right)$, senior emp. rate $=N^{s}$, junior emp. rate $=U^{j}$, labor share $=\left(w^{j} N^{j}+w^{s} N^{s}\right) /(F-a V)$, seniority premium $=w^{s} / w^{j}-$ 1. Shocks to matching efficiency match the evolution of the aggregate unemployment rate. Scenarios (i)-(iv) correspond to simulations for the period 1968-2007.

for the longer future, capital stock and labor demand rise. As the seniors work longer to save more, they increase their labor supply. The senior employment rate thus increases unambiguously. The effect on the junior employment rates is ambiguous. On one hand, the juniors benefit from higher labor demand. On the other, they are crowded-out by the seniors. In France, the second effect is stronger and the junior employment rate slightly decreases. In Germany, the first effect is stronger and the junior employment rate increases. The seniority premium and labor share remain almost unaffected.

Taken together, in column (iii), transfers and aging alone are largely insufficient to match the labor market evolutions. While the senior participation and employment rates in France are somehow matched, this is not the case in Germany. Senior participation actually rises in the German simulation because the rise in the pre-retirement replacement rate is relatively small and thus the (positive) effect of aging outweighs the (negative) one of the old-age welfare. The changes in the junior employment rate, seniority premium and labor share remain unexplained. 
Table 3: Exogenous shocks : 1968-2007

\begin{tabular}{lcccc}
\hline France & & $\mathbf{1 9 6 8}$ & $\mathbf{2 0 0 7}$ & Change \\
\hline Transfers & $\rho^{i}$ & 0.215 & 0.32 & $+48.8 \%$ \\
Longevity & $\sigma$ & 0.62 & 0.91 & $+46.8 \%$ \\
Bargaining power & $\eta$ & 0.79 & 0.64 & $-19 \%$ \\
Matching efficiency & $\bar{m}$ & 0.98 & 0.65 & $-33.7 \%$ \\
& & & & \\
\hline Germany & & $\mathbf{1 9 6 8}$ & $\mathbf{2 0 0 7}$ & Change \\
\hline Transfers & $\rho^{i}$ & 0 & 0.075 & +0.075 \\
Longevity & $\sigma$ & 0.60 & 0.85 & $+41.7 \%$ \\
Bargaining power & $\eta$ & 0.75 & 0.67 & $-10.7 \%$ \\
Matching efficiency & $\bar{m}$ & 0.99 & 0.79 & $-20.2 \%$
\end{tabular}

$\rho^{i}$ is the early retirement benefit ratio, $\sigma$ is the survival probability at age $65, \bar{m}$ is the matching efficiency, $\eta$ is the worker bargaining power.

\subsection{Bargaining power and matching efficiency shocks: estimation and prediction}

Although pre-retirement benefits, combined with population aging, could in some cases (France) explain the rise in early retirement, they are largely insufficient to match other labor market evolutions. We therefore consider two additional shocks that have hit European labor since 1960s - the structural changes in the form of lower bargaining power of workers and lower matching efficiency in the labor market. To assess their effect on the labor market, ideally we would like to know the actual magnitudes of the shocks to the bargaining power and matching efficiency between 1968 and 2007. However, this information is at best rudimentary. We therefore use the model to estimate the two unobserved exogenous shocks by minimising the deviation between the actual and simulated data for 2007 for the endogenous variables of interest in Table 2. ${ }^{12}$ The isoquants for the log-error are displayed in Figure 2. The estimation implies a $19 \%$ and $33.7 \%$ decline in the bargaining power and matching efficiency, respectively, in France and a $10.7 \%$ and $20.2 \%$ decline, respectively, in Germany. These values are compatible with the empirical evidence reported in section 1.

Our estimates lead to a jointly counterfactual exercise presented in columns (iv) and (v) of Table $2 .{ }^{13}$ The decrease in worker's bargaining power (column (iv) of Table 2) causes a direct fall in wages and reduces the senior participation rates. Pre-retirement benefits, being indexed on wages, fall as well

\footnotetext{
${ }^{12}$ More precisely, for all combinations of $(\bar{m}, \eta)$ such that $0.6 \bar{m}_{1968}<\bar{m}_{2007}<\bar{m}_{1968}$ and $0.6 \eta_{1968}<\eta_{2007}<\eta_{1968}$, we simulate the model and compute error $\sum_{v \in V} \frac{\left(v_{\text {model }}-v_{\text {data }}\right)^{2}}{n}$, where $V$ contains senior participation rate, senior employment rate, junior employment rate, seniority premium and labor share, while $n$ is the number of items in $V$. As we assume that shocks take place equally each period, $\bar{m}_{1988}=\frac{\bar{m}_{1968}+\bar{m}_{2007}}{2}$ and $\eta_{1988}=\frac{\eta_{1968}+\eta_{2007}}{2}$. We also try an estimation under less restrictive conditions with $\bar{m}_{1968}<\bar{m}_{2007}$ and $\eta_{1968}<\eta_{2007}$, but fail to obtain convergence.

${ }^{13}$ As the the effects of the two shocks often offset each other, the estimation of each shock individually would produce smaller shock magnitudes as well smaller deviations from 1968 baselines for the variables of interest.
} 
Figure 2: Isoquants for the log-error between the simulated and real labor market data.
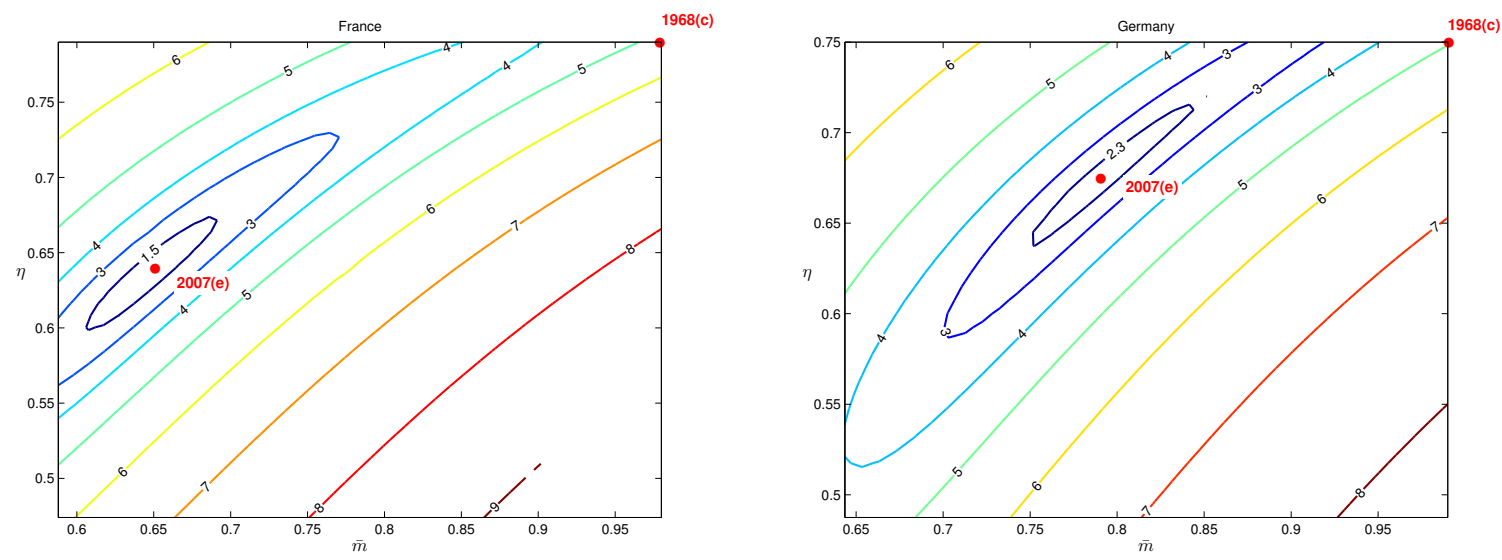

Estimated parameters: worker bargaining power $(\eta)$ and matching efficiency $(\bar{m})$

but this is insufficient to halt the entry of seniors into inactivity. The effect is stronger in France essentially due to higher reservation wages. Senior workers in France have a high disutility of work (high $D n-D u$ in Figure 1) and are thus less likely to bargain into lower wages, unlike the German senior workers whose wage curve is steeper (low $D n-D u$ ). Since retirement benefits are indexed on senior wages, the generosity of the French pension system is not much affected and the seniors choose to preretire. In Germany, the disutility of work is low and there are no pre-retirement benefits to start with. For the same reason the decomposition of employment response in France in Germany differs. Lower wages stimulate the opening of new vacancies and increase total employment, but the old and the young in the two economies are affected differently. Lower bargaining power mainly reduces junior wages in France whereas it reduces all wages in Germany, as manifested by the evolutions of the seniority premium. Put differently, the vacancy increase mainly benefits the junior workers in France. In Germany, new jobs are filled by both the young and the old. Finally, the bargaining power shock is sufficient to accounts for the lower labor shares in both economies. In sum, the declining bargaining power matters for the fall in the senior participation rates and the labor share, while its effect on employment is ambiguous and depends on the reservation wages and the generosity of old-age welfare. Bargaining power also matters for the evolution of the seniority premium in the French simulation.

The effect of a negative matching efficiency shock is presented in column (v) of Table 2. As lower matching efficiency reduces the probability for the firms to fill a vacancy, the effect on the seniors is two-fold. On one hand, they are negatively hit by the lower labor demand and falling wages. On the other, they are encouraged to increase their participation to compensate for the lower early-retirement transfers. In both countries the senior participation rate is reinforced. This is the case especially in France 
Figure 3: Shock decomposition for the simulations 1968-2007

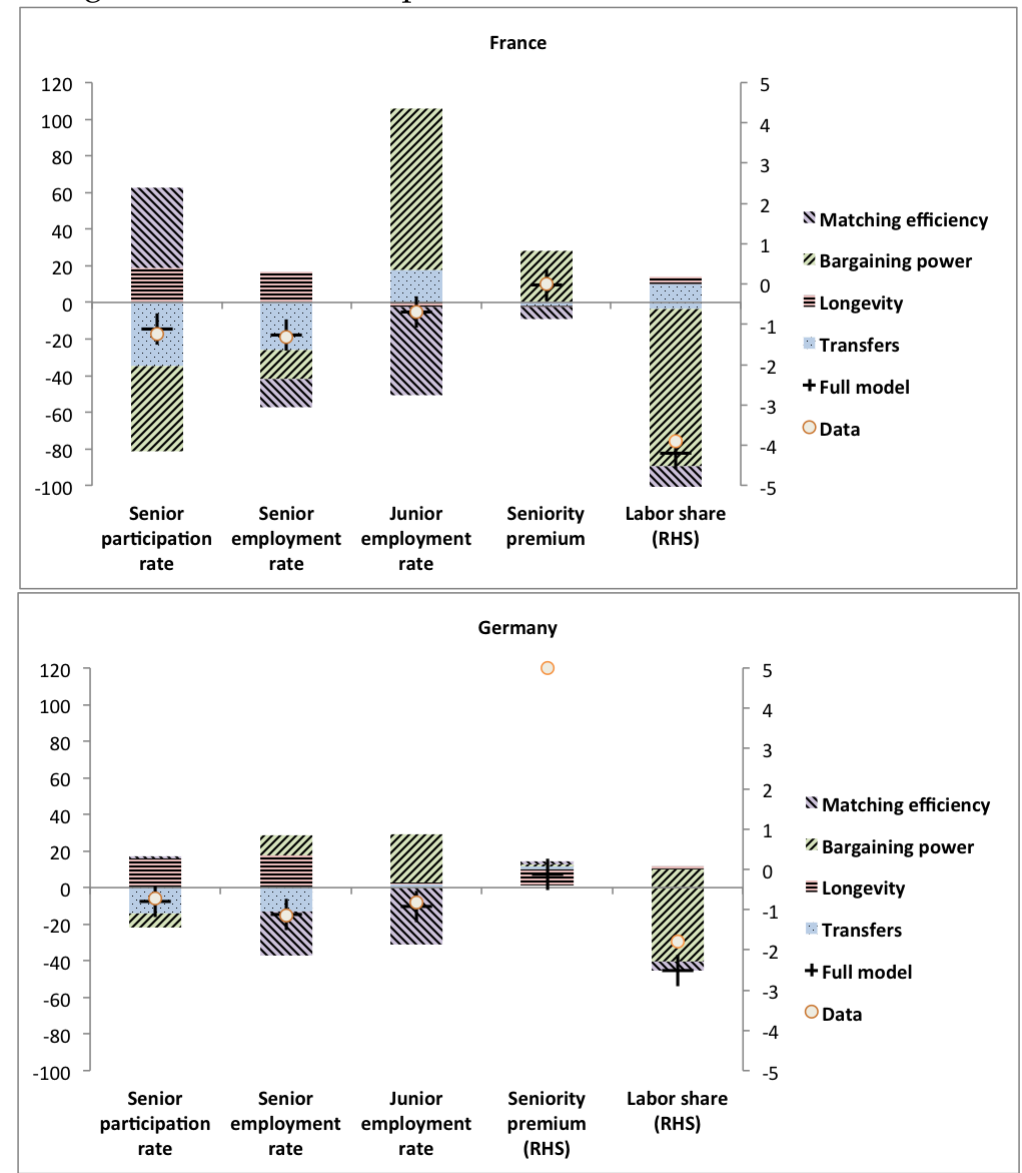

Vertical axis represents percentage point deviation from the 1968 steady state.

since benefits in Germany are negligible to start with. In both economies the senior employment rates fall as the lower demand dominates over the higher supply of senior labor. Junior employment rates fall unambiguously. Matching efficiency thus emerges as an important force behind both the (positive) senior participation and (negative) employment changes. It has little effect on the labor share, and largely counterfactual or no effect on the seniority premium.

The four shocks - to the pre-retirement benefits, aging, matching efficiency and bargaining power - are combined in scenario (vi) in Table 2, while Figure 3 plots the shock decomposition as well as the match between the real and artificial data. ${ }^{14}$ The model's predictions match the data well. For France the model explains $86 \%$ of the rise in early retirement. In France, comparing to scenario (iii) with transfers and aging only, the model matches better the participation and employment rates, as well as the seniority premium and labor share. The senior labor force participation rate is matched better

\footnotetext{
${ }^{14}$ The model features non-linear effects and therefore the sum of effects due to individual shocks is not equal to the deviation obtained by the model with all shocks included.
} 
due to the (positive) effect of the matching efficiency; senior employment falls further due to the (negative) effect of both the bargaining power and the matching efficiency; junior employment is reduced by the declining matching efficiency; while the seniority premium and labor share are matched by the declining bargaining power. For Germany there is now a considerable improvement in the participation, employment and labor share responses, comparing to scenario (iii), although the model overestimates the fall in the senior participation rate by $1.3 \%$. The fall in the bargaining power is important in matching the senior participation rate and the labor share. The matching efficiency is instrumental to reproducing the senior and junior employment rates. The model only misses the rise in the seniority premium in Germany. The reason can be gauged from Figure 1. The German case corresponds to low reservation wages $\left(D_{n}-D_{u}\right) / P_{d}$, and German bargaining power is close to high $\eta$, the region where a fall in the bargaining power induces a fall in the seniority premium. ${ }^{15}$

\section{Discussion}

In this work we suggest that the structural change in the labor markets is important not only in accounting for the rise in early retirement in Europe but also in matching the evolution of other labor market variables. We show that lower bargaining power of labor acts as an important discouragement to participation because it induces lower wages. On the other hand, lower matching efficiency encourages participation as senior workers try to compensate for the negative effect of the falling wages on the expected retirement transfers. The two structural changes matter more in France than Germany, not only because the shocks are larger in magnitude in France (Table 3), but also because of larger rigidities in the form of higher disutility of work and more generous old-age welfare in France. Our model also shows that the two structural shocks are instrumental in matching the artificial to the actual data for other labor market outcomes (Figure 3). Beyond senior labor force participation, matching efficiency is essential for the determination of the senior and junior employment rates. In turn, the bargaining power drives all the variables of interest - the participation and employment rates, as well as the seniority premium and labor share. The model only fails to account for the rise in the seniority premium in the relatively flexible German economy.

An appealing feature of the model presented is its parsimony. Despite its simplicity, the model

\footnotetext{
${ }^{15}$ An obvious extension that could possibly remedy this is the introduction of unemployment benefits to the model. Benefits would likely increase the reservation wages of seniors by more than juniors because they are indexed on higher wages and therefore, as could be seen from Figure 1, could produce a rise in premium when the bargaining power declines. We have tested an alternative model, with unemployment benefits included, but we still fail to reproduce the rise in premium in Germany. It is likely that additional shocks would be required, for instance a rise in unemployment replacement ratio over time. However, while unemployment replacement rates rose substantially in Europe until 1970s, from 1970s onwards the changes in replacement rates have been limited. See next section for further discussion.
} 
includes a number of sophisticated mechanisms. One is the inter-temporal connection between senior and junior employment through the determination of junior wage. Thus policies encouraging early retirement, or shocks to longevity, have a bearing on junior employment not only through the more direct channel of job competition between the young and old. Another is the interaction between labor market institutions. Negative changes both to the bargaining power and matching efficiency, having bearing on wages and through them on retirement benefits, interact with the early retirement schemes in determining the participation decision of senior workers. The negative income effect due to lower benefits is not enough to halt the exit of seniors from the labor force when the bargaining power is reduced, but is sufficient when the matching efficiency falls. The degree of such interactions varies between the two countries because of the differences in the wage flexibility and generosity of old-age welfare. A crucial feature in our modelling strategy is the disutility of work which increases with age and has a considerable effect on wage flexibility. The disutility of work is higher in the French economy. Important differences thus emerge in how the senior labor force participation reacts to the structural change. The seniors in France are less likely to bargain into lower wages when their bargaining power falls which, combined with generous old-age welfare, induces them to retire more willingly. On the other hand, the seniors in Germany are little affected by the falling wages when the matching efficiency is reduced because they have low disutility of work and low retirement replacement rates.

A number of extensions to the model could be envisaged. First, beyond matching efficiency, a larger array of factors have been proposed in literature to explain the European labor market dynamics, especially the rise in unemployment since 1970s. They include, for instance, unemployment insurance which our model ignores. Compiling data from various sources, Marchiori et al. (2011) show that unemployment insurance rose substantially in Europe between 1940s and 1970s. However after 1970s, the changes in the generosity of the unemployment insurance schemes were limited. As we start our model in 1968, we believe that the subsequent changes in unemployment replacement rates are less important than the rise in early retirement benefits, the decline in bargaining power and the fall in the matching efficiency, all of which gained speed starting in 1970s. Moreover, unemployment insurance itself may adversely affect the matching efficiency, hence to maintain tractability we prefer to focus only on the matching efficiency shock.

Secondly, the drop in the labor share might also be related to other factors beyond the declining bargaining power of workers. It is widely believed that the declining bargaining power of labor vis-a-vis capital has been reflected in the declining labor share (Bental and Demougin (2010), OECD (2012a)). As mentioned in the introduction, this has resulted from the changing nature of bargaining arrangements and globalization, both of which have weakened the labor market position of workers vis-a-vis firms. 
However, other factors have also played an important role. Bentolila and Saint-Paul (2003) point to technological change and capital depending. Checchi and Penalosa (2010) find that minimum wages are associated with labor share changes in the opposite direction. Daudey and Decreuse (2006) consider the importance of more educated workforce that has mitigated the decline in the labor share in the OECD. What our model shows is that the bargaining power does matter for the labor market participation decisions, and its decline leads to participation changes in the direction consistent with the data. Increasing the number of free shocks further (now limited to $\eta$ and $\bar{m}$ ) would improve the match between the artificial and real data. At the extreme, a full identification scheme with the number of free shocks equal to the number of variables one wishes to reproduce would generate a perfect match.

\section{Policy Implications}

Proponents of early retirement measures believed that an exit of older workers from the labor market would make space for the employment of the young. Consistent with other work that explores labor market outcomes over the life cycle (for example, Hairault et al. (2010), Hairault et al. (2011), Chéron et al. (2013)), our simple three-generation model with labor market frictions demonstrates that such reasoning ignores the dynamic effects that an exit of older, and possibly more productive, workers might exert on the economy. In particular, our model predicts that - on one hand - the young benefit from lower job-competition from the old but - on the other - firms' incentives to open vacancies are reduced when they face of a smaller pool of job applicants. In our calibrated model for France and Germany, the former effect dominates, especially in the French economy characterized by a rigid labor market.

As the concern of governments has shifted to averting budgetary crisises looming in the light of rapid population aging, attempts to raise the retirement age, to lower the retirement benefits and to reform the pensions towards self-funding have all aimed at encouraging older workers to work longer. Germany, France and other European countries have undertaken such steps (OECD (2013b), OECD (2012b), OECD (2014b)). In France this has been met with much stronger opposition to the reform, including from the youths, which is consistent with our model that features a higher net disutility of work in France. Our model also predicts that the young in France might be more likely than their counterparts in Germany to gain from the early retirement of senior workers because higher seniority premia in France stifle the overall job creation.

The main feature of our model is its ability to illustrate the responses of the labor market to changes in the bargaining power of labor and the efficiency of matching workers to jobs. The bargaining power of labor has been falling for decades and the trend is unlikely to be reversed, especially in the 
context of the recent economic crisis. Ceteris paribus, we would expect more willingness on the part of the seniors to retire early, especially in France where reservation wages are relatively high. Indeed, since 2008 many firms in France have successfully offered pre-retirement options to their senior employees (OECD (2014a)). Second, with lower bargaining power, workers face downward pressure on wages. Comparing to the Germans, French older workers have been less willing to accept this, which is consistent with our model's predictions of the seniority premia. In line with the model, a number of German industries have successfully negotiated more flexibility with their workers, regardless of age (OECD (2012a)). In France, on the other hand, it has been the young who have suffered knock-on-effects of falling or stagnating real wages (INSEE (2015)). As job creation is currently low, this naturally translates into few vacancies but, as economy picks up in the future, it could be French younger rather than older workers who might benefit from a faster recovery of jobs.

Our model also predicts that young workers' employment would unambiguously benefit from more efficient labor markets, pointing to the desirability of measures that help workers find jobs. However, the model demonstrates an ambiguous effect of labor market efficiency on the labor force participation of the old, depending on the relative strength of the supply and demand for labor. On one hand, better matching of workers to jobs encourages job creation but, if higher wages translate to higher early retirement benefits, some seniors might retire early. This is more likely when the disutility of work is relatively high. However, if European countries progressively move away from generous pre-retirement measures and encourage workers to fund their own retirement plans, the incentive to pre-retire will weaken and higher matching efficiency will also benefit the labor force participation of older workers.

Finally, our model vindicates the virtue of longevity, in line with literature (for example, Bloom et al. (2007) and Bloom et al. (2014)). Longevity is likely to increase further and governments should encourage the development of medical technologies that enhance it. Our model predicts increases in the labor force participation of older workers as they expect to live longer and must save for longer future. This force will become stronger when pay-as-you-go pension systems are progressively replaced by fully-funded schemes. Although the model is ambiguous regarding the employment rate of the young when they are faced with the growing numbers of older workers, we assume that the young and the old are substitutes in production. In reality, they might be substitutes in some sectors but complements in others. 


\section{Conclusions}

We reexamine the determinants of the decline in the labor force participation of senior workers in Europe. An OLG model with labor market frictions allows us to consider the effect of structural changes in the labor market — the declining bargaining power of workers and matching efficiency — on the labor force participation decision of the elderly. This would not be possible in a purely neoclassical framework with perfectly competitive labor markets where no distinction is made between participation and employment. We find that the decline in the bargaining power of workers and less efficient labor markets have affected the early retirement in France and Germany since 1960s. The two shocks, combined with the rising early-retirement transfers and population aging, reproduce closely the joint evolution of the participation and employment rates, the seniority premium and the labor share.

\section{References}

Arpaia, A., Kiss, A., and Turrini, A. (2014). Is unemployment structural or cyclical? Main features of job matching in the EU after the crisis. European Economy - Economic Papers 527, European Commission.

Aubert, P. and Crépon, B. (2003). La productivité des salariés âgés: une tentative d'estimation. Economie et Statistique, 368(1):95-119.

Bental, B. and Demougin, D. (2010). Declining labor share and bargaining power: An institutional explanation. Journal of Macroeconomics, 32(1):443-456.

Bentolila, S. and Saint-Paul, G. (2003). Explaining movements in the labour share. Contributions to Macroeconomics, 3(1):Article 9.

Blanchard, O. J. and Diamond, P. A. (1989). The Beveridge curve. Brookings papers on economic activity, $1: 1-76$

Bloom, D. E., Canning, D., Mansfield, R. K., and Moore, M. (2007). Demographic change, social security systems and savings. Journal of Monetary Economics, 54:92-114.

Bloom, D. E., Canning, D., and Moore, M. (2014). Optimal retirement with increasing longevity. Scandinavian Journal of Economics, 116(3):838-858.

Buyse, T., Heylen, F., and de Kerchhove, R. V. (2013). Pension reform, employment by age, and long-run growth. Journal of Population Economics, 26(2):769-809. 
Checchi, D. and Penalosa, C. G. (2010). Labour market institutions and the personal distribution of income in the OECD. Economica, 77(307):413-450.

Chéron, A., Hairault, J.-O., and Langot, F. (2013). Life-cycle equilibrium unemployment. Journal of Labor Economics, 31(4):843-882.

Daudey, E. and Decreuse, B. (2006). Higher education, employers' monopsony power and the labour share in OECD countries. Technical Report 3631, MPRA, Munich.

de la Croix, D. and Michel, P. (2002). A Theory of Economic Growth: Dynamics and Policy in Overlapping Generations. Cambridge University Press, Cambridge.

de la Croix, D., Pierrard, O., and Sneessens, H. R. (2013). Aging and pensions in general equilibrium: Labor market imperfections matter. Journal of Economic Dynamics and Control, 37:104-124.

Dickens, W. T. and Triest, R. K. (2012). Potential effects of the Great Recession on the U.S. labor market. The B.E. Journal of Macroeconomics, 12(3):1-41.

Docquier, F., Paddison, O., and Pestieau, P. (2007). Optimal accumulation in an endogenous growth setting with human capital. Journal of Economic Theory, 134(1):361-378.

Duval, R. (2003). Retirement behaviour in OECD countries: Impact of old age pension schemes and other social transfer programmes. OECD Economic Studies, 2:7-50.

Entorf, H. (1998). Mismatch Explanations of European Unemployment: A Critical Evaluation. Springer, Berlin.

Fahr, R. and Sunde, U. (2004). Occupational job creation: Patterns and implications. Oxford Economic Papers, 56(3):407-435.

Fahr, R. and Sunde, U. (2006). Regional dependencies in job creation: an efficiency analysis for western germany. Applied Economics, 38(10):1193-1206.

Fahr, R. and Sunde, U. (2009). Did the Hartz reforms speed-up job creation? A macro-evaluation using empirical matching functions. German Economic Review, 10(3):284-316.

Gautié, J. and Schmitt, J. (2010). The impact of institutions on the supply side of the low-wage labor market. In Low-Wage Work in the Wealthy World, pages 147-180. Russel Sage Foundation.

Gruber, J. and Wise, D. A. (1998). Social security and retirement: An international comparison. American Economic Review, 88(2):158-163. 
Hairault, J.-O., Langot, F., and Chéron, A. (2011). Age-dependent employment protection. Economic Journal, 121(557):1477-1504.

Hairault, J.-O., Langot, F., and Sopraseuth, T. (2010). Distance to retirement and old workers' employment: the case for delaying the retirement age. Journal of European Economic Association, 8(5):1034-1076.

Heijdra, B. J. and Romp, W. E. (2009). Retirement, pensions and aging. Journal of Public Economics, 93(3-4):586-604.

Ibourk, A., Maillard, B., Perelman, S., and Sneessens, H. R. (2004). Aggregate matching efficiency: A stochastic production frontier approach, France 1990-1994. Empirica, 31(1):1-25.

INSEE (2015). Bases de données: Revenus-salaires. Paris.

Jackman, R. A., Pissarides, C. A., and Savouri, S. (1990). Labour market policies and unemployment in the OECD. Economic Policy, 11:449-90.

Khaskhoussi, F. (2009). Job-search effort, retirement decision and pension reform: A wage bargaining investigation. Economics Bulletin, 29(2):1255-1263.

Kindermann, F., Fehr, H., and Kallweit, M. (2013). Should pensions be progressive? European Economic Review, 63:94-116.

Layard, R. P., Nickell, S. J., and Jackman, R. A. (2005). Unemployment: Macroeconomic Performance and the Labour Market. Oxford University Press.

Lazear, E. P. and Shaw, K. L., editors (2009). The Structure of Wages: An International Comparison. University of Chicago Press, Chicago.

Ludwig, A. and Reiter, M. (2010). Sharing demographic risk - who is afraid of the baby bust?". American Economic Journal: Economic Policy, 2(4):83-118.

Marchiori, L., Pierrard, O., and Sneessens, H. R. (2011). Demography, capital flows and unemployment. CREA Discussion Paper Series DP 11-14, Center for Research in Economic Analysis, University of Luxembourg.

MaxPlanckInstitute (2009). The Human Life-Table Database. Max Planck Institute, Rostock, Germany.

McCall, J. J. (1970). Economics of information and job search. Quarterly Journal of Economics, 84(1):113126. 
Michel, P. and Pestieau, P. (2013). Social security and early retirement in an overlapping-generations growth model. Annals of Economics and Finance, 14(2):723-737.

Mortensen, D. T. and Pissarides, C. A. (1994). Job creation and job destruction in the theory of unemployment. Review of Economic Studies, 61(3):397-415.

Nickell, S. (2003). A picture of European unemployment: Success and failure. Technical Report 577, Centre for Economic Performance, LSE.

OECD (2004). Taxing Wages. OECD, Paris.

OECD (2012a). Employment Outlook 2012: Labour Losing to Capital. What Explains the Declining Labour Share? OECD, Paris.

OECD (2012b). OECD Pensions Outlook 2012. OECD, Paris.

OECD (2013a). OECD Labour Force Statistics. OECD, Paris.

OECD (2013b). Pensions at a Glance 2013: OECD and G20 Indicators. OECD, Paris.

OECD (2014a). Aging and Employment Policies: France. OECD, Paris.

OECD (2014b). OECD Pensions Outlook 2014. OECD, Paris.

Pissarides, C. A. (2000). Equilibrium Unemployment Theory. MIT Press, Cambridge, MA.

Schmitt, J. and Jones, J. (2012). Bad jobs on the rise. Reports and Issue Briefs 2012-23, Centre for Economic and Policy Research, Washington D.C.

Skirbekk, V. (2004). Age and individual productivity: A literature survey. In Vienna Yearbook of Population Research. Verlag der Österreichischen Akademie der Wissenschaften, Vienna.

Vallin, J. and Meslé, F. (2002). Tables de mortalité françaises pour les XIX et XX siècle et projections pour le XXI siècle. INED, Paris. 